\title{
Music Confucius Institute: Evaluating Its Approach as an Agent for International Chinese Music Dissemination
}

\author{
Wei Guo ${ }^{1} \&$ Sheng Bing $\mathrm{Li}^{1}$ \\ ${ }^{1}$ School of Education, South China Normal University, Guangzhou, China \\ Correspondence: Wei Guo, School of Education, South China Normal University, Guangzhou, NO. 55, Zhong \\ Shan Xi Lu, Tian He District, China. Tel: 86-186-6483-4920. E-mail: guowei_judy@hotmail.com
}

Received: January 27, 2016

Accepted: February 15, 2016

Online Published: February 22, 2016

doi: 10.5539/hes.v6n1p182

URL: http://dx.doi.org/10.5539/hes.v6n1p182

\begin{abstract}
The paper identifies the educational and presentational functions of the Confucius Institute (MCI) at the Royal Danish Academy of Music (RDAM) as its core approaches which mostly influence Chinese cultural dissemination in its host country. The MCI's utilization of the two dissemination approaches aligns with the "receiver-centered" framework introduced by Jiang and Zhang (2009), providing three concurrent strategies-Localization, "Entertainalization" and Regulation (LER) - in order to enhance the dissemination of Chinese culture to the general public. Through detailed analysis of somewhat limited pre-existing research findings and literature, this article makes the claim that the MCI has achieved positive results in its two functional domains, meeting its overseas audience's needs at various levels whilst supporting Chinese cultural dissemination internationally. This article concludes on the prospect that more MCIs are expected to be established around the world in order to satisfy the growing needs of authentic studies in Chinese musical traditions without travelling to China, as well as to support Chinese cultural communication with the rest of the world.
\end{abstract}

Keywords: Chinese music overseas education, Music Confucius Institute, international cultural dissemination, higher music education, cultural exhibition

\section{Introduction}

\subsection{International Cultural Dissemination in Today's World}

In this post-modern era of pervasive internationalization and globalization it is evident that international cultural dissemination is becoming the social media by which a nation's cultural influence impacts upon the world. In conjunction with other social media, such as intercultural communication, cultural exchange, and cultural promotion, international cultural dissemination is receiving increased attention in academic fields (Yang, 2012).

International cultural dissemination is synonymous with cultural diffusion; it is the process of introducing one country's cultural traits which are recognized as the disseminated message of cultural origin to another country's culture (Liu, 2013; Axelrod, 1997). Cultural traits include various aspects such as language, history, the arts, literature, cuisine, and so on. The dissemination of popular multicultural traits conveys the essence of a country's particular culture, influencing the lifestyles, tastes, hopes and desires, mores and norms of almost each and every nation in the world (Hirst \& Thompson, 1999). A complete cultural dissemination cycle comprises four key elements: the message origin/sender, the message, the disseminating channel(s), and the message receiver/the audience (An \& Zhu, 2013; Jiang \& Zhang, 2009). However, Liu (2013) and Chen (2008) claimed that according to Wilbur Schramm, a founder of Information Dissemination, the "dissemination effect on the receiver" should be included as the fifth element.

Conditionally, however, many researchers argue that cultural dissemination should be a two-way process in that the message sender needs to be well-grounded not only in their own cultural traits, but also in those of the recipient country. Some researchers assert that an awareness of differences between the culture of origin and the recipient culture enables practitioners to disseminate messages more effectively with their audience (Bellou, 2014; Zaharna, 1995). Munter (1993) stated clearly that "We need to remember that other cultures do not necessarily share our behaviors-verbal or nonverbal" (p. 69).

In agreement to the two-way dissemination process, Jiang and Zhang (2009) argued that the entire process of cultural dissemination should pay extra attention to the audience - the message receiver - in order to enhance the 
effectiveness of the dissemination. Based upon MacInnis and Jaworski's integrative AMO (Ability/Motivation/Opportunity) factors, which were generated from Petty and Cacioppo's Elaboration's Likelihood Model of Persuasion (ELM) theory - the latter being recognized as the most influential theory in the past thirty years - Jiang and Zhang (2009) devised a "receiver-centered" strategic framework to address the recent phenomenon of rapidly developing international Chinese cultural dissemination. They claimed that Localizing and "Entertainalizing" the disseminated message, in conjunction with Regulating the disseminating process (LER), are able to enhance the receiver's reprocessing of the message, so as to further absorb the message.

\subsection{China's Resurgence in International Cultural Dissemination}

Since the introduction of Deng Xiaoping's "Reform and Open-door" policy of 1978, China's economy has grown exponentially whilst the nation's international impact has strengthened markedly. Subsequently, within a relatively short time-frame, there has been a growing popular demand for Chinese studies on a global level (Guo, 2012; Ding \& Saunders, 2006; Zeng, 2006). In order to meet this demand, the Chinese government has established a series of innovative policies to encourage the dissemination of Chinese culture around the world. According to the Global Dynamic Database Resource on Chinese Culture (GDDRCC), China's average growth on core cultural products and cultural service exportation between 2001 and 2010 was $15.9 \%$ and $28.7 \%$, respectively. As of 2014,145 foreign governments have signed collaborative agreements for almost 800 yearly cultural communication projects with the Chinese government (Beijing Foreign Studies University, 2015).

Amongst various Chinese cultural dissemination bodies, the Confucius Institute is one of the most prominent (Li \& Tian, 2015; Hartig, 2011). As a government-subsidized, non-profit international cultural dissemination agent, the Confucius Institute aims to provide educational and disseminative services on $\mathrm{Han} \mathrm{Yu}-$ the official Chinese language - and Chinese culture in countries and regions where demand is high. According to the official website of the Confucius Institute (Hanban, 2016), over the past 11 years, there have been 500 Confucius institutes established in 125 countries with 200 or more universities in over 70 countries currently in progress founding new Confucius institutes. According to $\mathrm{Li}$ and Tian (2015), Confucius Institute has been recognized as the largest international higher education collaborative project in the world, to date.

In order to meet the world needs in terms of specific aspects of Chinese culture (for example, Chinese opera, tourism and business, traditional Chinese medicine, martial arts), the Confucius Institute has oriented its school mission in diverse directions. Since 2008, a series of highly-specialized Confucius Institutes have been established around the world. The Music Confucius Institute (MCI) at the Royal Danish Academy of Music (RDAM) is one of particular note, which focuses on Chinese music culture, representing the one and only music Confucius Institute in the world at present (Hou \& $\mathrm{Li}, 2015)$.

\section{Research Methodology}

This research study focused on the MCI's establishment background, educational and presentational servicing functions, and the role it plays as an agent of Chinese music culture dissemination. In consideration of MCI's uniqueness, innovativeness, and the scarcity of pre-existing research, the researchers decided to utilize virtual ethnography, semi-structured interview and observation for data collection under a qualitative research design.

\subsection{Virtual Ethnography}

Virtual ethnography was used to gather data on the participants' opinions towards and experiences with MCI through a social network which constantly provides large swathes of information, either meaningful or trivial in nature, but all generated by individual members of the online community. Some researchers agree that in comparison to the traditional ethnography conducted by a research team, virtual ethnography allows solo researchers to investigate the research subject from different angles at the same time. Although it is a process of intermittent engagement, it is equally important as any long term immersion for it provides in-depth information on the target community through grounding in the one community 24/7 (Hine, 2000; Evans, 2010).

Despite the fact that the use of virtual ethnography has been broadly advocated within the domain of qualitative research, it is necessary to be aware that this research method is used on a partial basis only (Zhang, 2015; Gao \& $\mathrm{Li}, 2015)$. Therefore, semi-structured interviews and observations were utilized in this study to ensure cross-validation of the data collected.

\subsection{Semi-Structured Interview and Observation}

Semi-structured interviews are commonly used in qualitative research in social science and behavioral studies, allowing "a greater flexibility of coverage" whilst leading the interview "to go into novel areas" with richer data (Smith \& Osborn, 2003, p. 57; Bresler, 1995). The researchers chose five key staff members from both the MCI's Chinese and Danish panels as interviewees, including the Manager of the MCI Office, the Project Manager, the 
only government-sponsored music teacher, the Director of MCI at RDAM and the Secretary of Foreign Affairs and Administration of the MCI Office. The reason for choosing these interviewees was because every one of them plays a different, yet important role in MCI's operations. Moreover, the researchers also conducted semi-structured interviews with one Director and two teachers who had previously worked at other Confucius institutes in France and Turkey. The gathering of all these interviewees' responses was regarded valuable in terms of gaining a comprehensive and thorough understanding of the subject of this study: MCI.

Observation is another commonly used data collecting tool in the field of qualitative research, through which the researchers are more able to fully immerse into the subjective dimensions of the phenomenon he/she studies for detailed and deeper understanding of the research subject (Johnson \& Christenson, 2004; Burns, 1995). The researchers' observation was conducted in CCOM where the MCI Office is located and where the MCI's teachers and volunteers are trained.

\section{Results}

\subsection{Profile of the MCI at RDAM}

In June 2012, upon the authorization of Hanban - the Confucius Institute Headquarters - the MCI at RDAM was jointly founded between the Central Conservatory of Music (CCOM) in Beijing and the Royal Danish Academy of Music (RDAM) in Copenhagen. Being the world's first and only Confucius Institute specializing in Chinese music instruction and dissemination, $\mathrm{MCI}$ is open to anyone who is interested in traditional and modern Chinese music, facilitating the cultural, musical, and diplomatic exchange between the two collaborative institutes as well as between China and Denmark. Its core duties include providing Chinese music-oriented instructions, lectures, concerts and various cultural activities in Denmark, and to an extent, other European countries (CCOM, 2015; RDAM, 2015).

\subsection{The Two Core Servicing Functions of MCI}

\subsubsection{Educational Function}

On campus teaching in MCI at RDAM. As mentioned previously, MCI is a Confucius Institute specializing in Chinese music education and exhibition. The collaborative founders of MCI are two reputable music institutes, one from China and the other in Denmark. It therefore adheres to Chinese music teaching and instrumental instructions as its signature functional service. According to the Project Manager of MCI.

There have been three groups of teachers sent to Denmark to present, including one Government-Sponsored music instructor with a specialty in Guqin, one Government-Sponsored Chinese language teacher and 17 volunteers majoring in different music disciplines (Interview with the Project Manager (IPM), 2015/5/14).

These teachers are responsible for the teaching of five courses currently offered on-campus which include Chinese Percussion Instrumental Ensemble, Chinese Opuses Chamber Music, Chinese Music Appreciation, Chinese Instrumental Performance, and Chinese Language, encompassing the disciplines of Chinese music, Chinese culture and Chinese language (CCOM, 2015). So far, over 110 students have attended the MCI courses on a weekly basis as of May, 2015.

High School Project. Delivering Chinese music education to the younger generation is another major approach the MCI utilizes for cultural dissemination. The High School Project is one of MCI's major cross-cultural projects, providing Chinese language, culture, and music related instructions, teaching materials, performances and workshops which can also be included in the Danish National Curriculum for high school students involved in Chinese studies. According to the MCI's official statistics, over 1500 students from 20 different high schools have participated in the project in 2014, of which more than 1000 have become registered members with MCI upon the approval of their applications for memberships. As the founder of the High School Project, the Director of MCI at RDAM further explains that the project aims to help students gain knowledge and skills about Chinese music, language and culture through various methods (IDMR, 2015/9/12). She further states that it is hoped that the learning experiences through the High School Project can "simultaneously provide students with inventive views in their cross-cultural studies" whilst developing and enhancing their inter-cultural perspectives and cultural comparison skills in order to advance their Chinese studies (IDMR, 2015/9/12).

\subsubsection{Presentational Function}

Performance and exhibition. MCI regards cultural dissemination and promotion as its core mission, and performance and exhibition are the two major tools utilized for this purpose. In conjunction with the voluntary staff members, the Guqin instructor maintains that:

Organizing and delivering Chinese-culture-oriented concerts and musical activities are considered most influential 
and rewarding in terms of cultural dissemination and student recruitment (IG, 2015/6/18).

She further states that because MCI is a government-supported cultural promotion agent, the performances it delivers are often at the invitation of the Chinese Consulate in Denmark and other European countries which enable the Chinese culture - in particular Chinese music culture - to be disseminated on an "upper echelon" social level. On the other hand, the Guqin Instructor points out that "We also present cultural exhibitions via music items on as many occasions as possible, for example, local cultural activities" (IG, 2015/6/18). All music items are tailor-made according to the audience's particular requests, festive themes, and cultural exchange purposes. It is worth stressing that despite the fact that all performances and exhibitions are Chinese culture oriented.

The artists always make a point of integrating Danish music and/or western music into the program in order to demonstrate respect to the local culture and the Confucius Institute's belief in "harmony with different perspectives" (Interview with the Manager of MCI Office (IMMO), 2015/1/14).

Academic and research. The researchers believe that the academic and research activities MCI conducts are a means of demonstrating operational progress, research findings, and future research plans, and therefore has classified this service under the presentational function rather than the educational function.

Academic and research activities have always been strongly encouraged at the MCI amongst both teaching staff and students. This has been verified by the Manager of the MCI Office, who believes that developing teaching materials for students at different levels is an illustration of our academic mission (IMMO, 2015/1/14). This poses a rather serious challenge as there is a need to research students' local culture and music history in order to integrate their pre-existing knowledge into the teaching materials. She stresses the importance of MCI's research and academic activities for promoting MCI's sustainable development, arguing that a cultural dissemination agent that revolves solely on practical activities without the integration of research "will not survive today's world under the forceful drive of cultural globalization and music internationalization" (IMMO, 2015/1/14).

According to the MCI's official handbook (CCOM, 2015), with the support of Hanban, MCI has successfully hosted the 1st High-Level International Forum on the Overseas Dissemination of Chinese Music Culture in December 2013. In September 2014, the MCI Office of CCOM has become the basis of the newly established Foundation for Chinese International Promotion, the centre for the "exchange and experience of Chinese and foreign music cultures". One of the purposes of the establishment of this foundation is to coordinate research institutes and talented researchers to contribute to the MCI's future development on an academic level (CCOM, 2015, p. 12).

\section{Discussion}

This article will now turn to a discussion on the efficacy of MCI's international cultural dissemination by analyzing how its two core servicing functions fulfill Jiang and Zhang's (2009) LER strategic criteria for elevating the future prospects of Chinese cultural dissemination.

\subsection{Receiver-Centered Perspective and Receiver's AMO Factors}

Jiang and Zhang (2009) claimed that any effective method utilized in cultural dissemination should be generated from the receiver's needs.

The Manager of the MCI Office asserts that the MCI was founded not only for "advancing the educational and musical resources in both institutes", but also for "meeting the public's needs in studying authentic Chinese language, culture and musical traditions in their homeland" (IMMO, 2015/1/14). Ostensibly, the MCI was established to address both the RDAM's and the general public's demand for Chinese music culture at different levels, and is therefore taking a "receiver-centered" perspective in its process of Chinese cultural dissemination. This perspective is concordant with Jiang and Zhang's (2009) theoretical framework, whereby the process of international cultural dissemination involves the receiver's reprocessing of the message, and during this process the receiver reprocesses the message with greater motivation if the message suits their needs or interests.

Based upon this "receiver-centered" perspective, Jiang and Zhang (2009) further explained that in order to optimize the outcome of the receiver's reprocessing of the message during the process of international cultural dissemination, three influential factors must be considered: the Ability of message reprocessing, the Motivation of message reprocessing, and the Opportunity of message reprocessing (AMO). In the process of international cultural dissemination, Jiang and Zhang (2009) specified the three influential factors as follows:

Ability. Receiver's Ability of message reprocessing indicates the receiver's pre-requisite knowledge about the message and the ability of understanding the message. In MCI's dissemination process, the message receivers are consisted of all the audiences served by its two core functions, including students, local public, upper social class, 
officials and the Royal family in Denmark. It is readily accepted that the receivers' pre-requisite knowledge about and the understanding of Chinese language and Chinese music culture vary greatly. Alba and Hutchinson (1987) found that the capacity of pre-requisite knowledge about the disseminated message has a positive impact upon the reduction of difficulty level in message observation and evaluation. Burke, DeSarbo, Oliver and Robertson (1988) further argued that insufficient pre-requisite knowledge about the disseminated message can actually prevent the receiver from proceeding to sophisticated reprocessing.

Jiang and Zhang (2009) stated that in the process of international cultural dissemination the receiver should previously acquire knowledge of and understanding about the geographic, historic, ethnic and linguistic aspects of the message source country. In this research, school education, technology devices, media and public concerts are assumed to be the common dissemination channels through which most receivers that MCI serves can accomplish their pre-requisite stage of Chinese culture and traditional and modern Chinese music at primary level. However, sophisticated knowledge acquisition, including Chinese language, ethnic structure, cultural traditions, music history, and so on, often appears to be the missing link between the receivers' desire for further learning and their actual learning readiness. The Guqin instructor mentions that some professional music students are able to excel in the learning of a novel Chinese instrument but the language barrier and their lack of background knowledge prevent them from understanding the music and accomplishing their performance at a greater level (IG, 2015/6/18). It is safe to say that the receivers' reprocessing on the message the MCI sends out relies greatly on a comprehensive intellectual framework encompassing Chinese language, culture and music traditions which enables them to combine their pre-existing knowledge about China with their own country and the rest of the world.

Motivation. Receiver's Motivation for message reprocessing indicates the desire to reprocess the message. Some researchers define receiver's motivation for message reprocessing with words like force, drive, urge, wish, desire, but mainly within the fields of commerce and marketing. When it comes to international cultural dissemination, Jiang and Zhang (2009) believed that the receiver's motivation for message reprocessing should cover aspects pertaining to: (a) The message's relativity to the receiver; in other words, the relativity between the locus culture and the receiver has positive impact upon the receiver's motivation for message reprocessing, (b) Receiver's needs for understanding the locus culture at a sophisticated level, particularly when the receiver requires personal cultural immersion in the country, (c) Receiver's critical thinking ability. Jiang and Zhang (2009), however, indicated that unlike the first two aspects, the receiver's critical thinking ability is purely an individual aspect which is not necessarily considered as an influential factor in the general effectiveness of receiver's motivation for message reprocessing. This viewis not shared by the researchers who believe the contrary, that critical thinking ability on the receiver's part can be crucial in determining both level of and reason for motivating message reprocessing.

The receivers that MCI deals with generally have a rather basic understanding about China. However, aspects such as educational internationalization, cultural globalization, media popularization and so on have indirectly influenced the receivers in becoming more interested in Chinese studies, especially under the rapid development of the Chinese economy in the last two decades (IMMO, 2015/1/14). Many students who had learned under the Guqin instructor expressed their strong desires to travel to China to gain short-term living experience (IG, 2015/6/18). To these receivers, the relativity level between them and message of Chinese culture is higher than the relativity levels for Chinese language and the relativity level for Chinese music.In regards to professional music receivers, the Manager of MCI Office asserts that prior to the joint founding of the MCI, the RDAM as a reputable international music institute had already established a solid collaborative relationship with CCOM over many years. Therefore, the relativity between the professional music students at RDAM and the message involving Chinese music studies seems to be greater than other receivers. Needless to say, sophisticated music studies do require a concrete cultural foundation, ideally also including a language foundation. When speaking of the relativity levels between professional music receivers and messages involving general Chinese culture, Chinese language and Chinese music, there are no major hierarchical differences.

Opportunity. Receiver's Opportunity of message reprocessing indicates the suitability of the environment, wherein the message is received, for stimulating the message reprocessing. Unlike Ability and Motivation, the Opportunity of message reprocessing is not directly under the control of the receiver. In its original fields of commerce and marketing, the opportunity of message reprocessing has significant impact upon the environment and the time duration for the completion of reprocessing. In the field of international cultural dissemination Jiang and Zhang (2009) argued that the opportunity of message reprocessing should encompass the following four aspects: (a) the channels of receiver's access to the locus culture; (b) the possibility of receiver's access to the locus culture; (c) the consequence of the receiver's access to the locus culture; and (d) the time duration of each receiver's access to the 
locus culture. Moreover, An and Zhu (2013) state that theavailability ofdissemination channels for accessing of the locus culture and the number of the channels provided in the receiver's country are recognized as the most important factors amongst all aspects in consideration of message reprocessing. The smooth flow of the former enables the completion of the message reprocessing, whilst the latter influences the possibility, frequency and duration of receiver's access to the locus culture which eventually determines the effectiveness of the reprocessing.

When considering the diverse range of the receivers the MCI deals with, it is assumed that the availability and number of the dissemination channels and the frequency and duration of receiver's accesses to the locus culture vary greatly. There is an overall consensus from CCOM interviewees' responses that despite the provision and diversity of the channels for Chinese cultural dissemination in Denmark, there are undeniable limitations and thus there exists a strong demand for ongoing development (IG, 2015/6/18; IMMO, 2015/1/14; IPM, 2015/5/14; ISFAA, 2015/1/14). Such growing demand has become the underlying impetus for the founding of the MCI. The Manager of MCI Office further asserts that one of the MCI's developing aims is to provide a broad range of dissemination channels that meet receivers' needs at all levels and to enhance the frequency, duration, and stability of their access to Chinese studies in their homeland (IMMO, 2015/1/14).

Based upon the analyses of the three influential factors (AMO) of the receivers that MCI deals with, the researchers will now discuss how the MCI's two servicing functions meet the three strategies Jiang and Zhang (2009) provided for the overall enhancement of Chinese cultural dissemination around the world. These three strategies are localizing the message, "entertainalization" of the message, and regulating the dissemination process. The three strategies were generated to address the three influential factors, Ability, Motivation and Opportunity, respectively.

\subsection{Localizing the Message - A Strategy to Enhance a Receiver's Ability}

Jiang and Zhang (2009) suggested that in order to optimize the effectiveness of a receiver's ability for message reprocessing during the process of Chinese cultural dissemination, localizing the message is imperative and that the completion of localization is the completion of linking both cultures. It is apparent that the implementation of message localization is seen in both MCI's two core servicing functions.

Within the MCI's educational function, message localization is implemented in all teaching activities, but is first and foremost utilized in the development of teaching materials. The Guqin instructor shares that even though it is "extremely" difficult for the teaching staff to develop the teaching materials in conjunction with the local culture, it always ends up becoming one of the most rewarding projects for them. The link between the Chinese and local elements not only helps students accelerate their Chinese studies but also provides a solid grounding for the development of their cross-cultural perspective (IG, 2015/6/18). In terms of the implementation of message localization within the presentational function, the Manager of MCI Office argues strongly by stating that "We do not promote Chinese culture-we share it instead" (IMMO, 2015/1/14). This is because such culture sharing always involves both message origin and message receiver, not only demonstrating the respect for the receiver's culture but also recognizing the importance of the link between both cultures. In most MCI's presentational activities, the integration of both Chinese and local culture is always the underlying theme with emphasis on the former. In the Handbook outlining the celebration of the 10th anniversary of Confucius Institute series music culture exhibition and performance, it is stated that the series of activities organized by MCI "feature the integration of the traditional and the modern, the East and the West", with the interaction between the artists and local audience as always being the focus of the activities (CCOM, 2014, p. 2).

Instead of accessing and reprocessing the disseminated Chinese culture per se, message localization utilized in MCI benefits receivers' access to the disseminated message through a readily-built foundation formed by their local culture and their pre-requisite knowledge of and understanding of Chinese culture. Consequently, the receivers' ability of message reprocessing is enhanced without any forceful or extrinsic drive, and the effectiveness of the cultural dissemination is assumed to be elevated.

\section{3 "Entertainalizing" the Message - A Strategy to Enhance a Receiver's Motivation}

Jiang and Zhang (2009) explained that the strategy of "entertainalizing" the message is to be used for stimulating the receiver's motivation for message reprocessing. The core influential factor for enhancing receiver's motivation is the receiver's interest in the origin culture/country. In the process of Chinese cultural dissemination, message "entertainalization" means to increase the attraction level of disseminated culture whilst maintaining an appropriate profile of the country. The implementation of message "entertainalization" appears to be evident in MCI's activities under both its educational and presentational functions.

Amongst the multiple elements of Chinese culture, music and arts are two major aspects readily accepted by 
foreigners as their entertainment potential generates greater inspiration, creation, and collaborations across cultural and linguistic borders (IMMO, 2015/1/14; RDAM, 2015). Music-oriented language and cultural activities enable MCI's dissemination experiences to be more effective and inspirational. In agreement with the Manager of MCI Office, the Deputy Manager of Hanban proposes that the future development of the Confucius Institute will draw support from MCI and its music cultural exchange platform to improve the overall effectiveness of Chinese music and arts cultural dissemination, whilst uplifting China's cultural communication with the rest of the world (CCOM, 2014). The Guqin instructor observes that music immediately and effectively reduces the distance between teachers and students, and artists and audiences, which is conducive in making MCI's teaching and demonstrational tasks being conducted within an atmosphere of relaxation and enjoyment (IG, 2015/6/18). The music-oriented activities conducted under MCI's educational and presentational functions fit into Jiang and Zhang's (2009) strategy of message "entertainalization" in the process of Chinese cultural dissemination. Its music-oriented dissemination method is regarded as being of prime importance in enhancing receiver's motivation for message reprocessing which directly influences the effectiveness of the overall dissemination.

\subsection{Regulating the Process: A Strategy to Enhance a Receiver's Opportunity}

In the process of international cultural dissemination, the receiver's opportunity for message reprocessing depends on his/her access to the origin culture/country, with the possibility, frequency and duration as determining elements to the access. Access to the origin culture, argued Jiang and Zhang (2009), is increased by regulating the dissemination process effects upon these determining elements.

One of the purposes of founding MCI is to provide regular educational and presentational activities for audiences in the host country who have a strong desire for not only appreciating Chinese music, but also studying it and other cultural elements associated with Chinese music. The Guqin instructor explains that the regulated routine of teaching and exhibiting activities is a means of demonstrating MCI's professionalism. All courses offered at MCI and teaching activities hosted at registered high schools are operated on a weekly basis, enabling students' access to their studies and progress in accordance with the set curricula, especially in instrumental and language studies (IG, 2015/6/18). Apart from regulating classes, performances and workshops, MCI has made a point of hosting international music camps and academic conferences about Chinese culture on a regular basis. The 1st Top Level International Forum on the Overseas Spread of Chinese Music Culture hosted in December 2013, the 1st Beijing/Tianjin Music Confucius Institute Music Summer Camp hosted in July 2014, and the 2nd Beijing /Yunnan Confucius Institute “International Music Summer Camp" hosted in July 2015, are prominent examples of MCI's regulated cultural dissemination approach (CCOM, 2015).

It is evident that the MCI's regulated operational approach fits Jiang and Zhang's (2009) process regulation strategy in Chinese cultural dissemination. The significant results MCI has achieved in the past three years have demonstrated that in order to optimize the effectiveness of international dissemination of Chinese culture, regulating the dissemination process is considered essential.

\section{Conclusion}

As a unique and innovative agent for Chinese cultural dissemination, $\mathrm{MCI}$ has been in operation for three years to date. Its significant achievements under both educational and presentational functions have gained $\mathrm{MCI}$ an internationally recognized reputation.

This article has highlighted the interview data collected from five MCI's core staff members regarding MCI's profile and its key servicing functions. Additional interview data provided by staff members at other Confucius Institutes concerning their perspectives on the significance of MCI's founding were also stressed. Based upon Jiang and Zhang's (2009) inventive LER strategies for enhancing the effectiveness of international Chinese cultural dissemination, this article took a detailed approach in analyzing the compatibility between MCI's operational approaches and the LER strategies. The authors also described the positive role MCI plays in the overall Chinese cultural dissemination whilst suggesting that more MCIs are to be established in the future around the world.

MCI has been managed to develop and deliver tailored instructions and performances for all socio-economic levels. It states on RDAM's official website that:

China is an important destination for both [sic] students, musicians and artists. By fostering links between Denmark and China among the newest generation of musicians, $[\mathrm{MCI}]$ open[s] up career paths for students who are interested in working in the arts in an increasingly multicultural world. Dedication, friendship and curiosity are invaluable to continuously foster creativity (n. p. n.).

It is imperative that MCI not only enables audiences access to Chinese studies in language, culture and music, but 
also provides them distinct skills for their potential career paths in the future. Johanna, a viola player who is completing her postgraduate at RDAM and is struggling with future employment, shares her experience in the 2nd Beijing/Yunnan Music Summer Camp, stating that such valuable experience of multiculturalism will definitely enhance her opportunity in acquiring a decent job position (Zhang, 2015).

Admittedly MCI is not the only dissemination agent of Chinese music culture. It is, however, it is the first to successfully integrated music dissemination with education. The Manager of MCI Office rightly pointed out that many people around the world have great passion toward Chinese music culture, and the demand for learning in their homeland has rapidly increased. MCI was successfully established to meet such demand by delivering highly professional and authentic Chinese music education (IMMO, 2015/1/14). MCI's music-oriented dissemination approach involving the implementations of localization, "entertainalization" and regulation, have provided a model for other Confucius Institutes and music cultural dissemination agents to adapt to and emulate. For other Confucius Institutes, regulating the process of cultural dissemination is an intrinsic characteristic feature, but localizing and "entertainalizing" the disseminated message are worth considering for ongoing improvements. For other music cultural dissemination agents, the entertainment factor is readily embedded within music itself, but message localization and process regulation are of use for purposes of future development.

The partnership between two reputable music institutes - one based in China and the other one overseas-support by the Chinese government, and overseas demand, underpins the establishment of MCI. The researchers strongly believe that to have these three predetermining factors in place is not overly difficult to achieve in other countries. From the perspective of the principal researcher who has lived, studied, worked and conducted research in Australia over a period of eleven years, it is feasible that there is fertile ground in place for the establishment of a Music Confucius Institute to be established in addition to the pre-existing seven Confucius institutes in Australia. The ongoing success of the seven Confucius Institutes can be attributed to the Chinese government's support for the dissemination of Chinese culture in catering to local demand for such in Australia. The researchers would advocate the need for one or more of the many reputable music conservatories in Australia to tender an expression of interest in hosting the establishment of an $\mathrm{MCI}$ in the near future.

The researchers, along with like-minded colleagues, could be called upon to negotiate and facilitate the founding of the first MCI in Australia and elsewhere so as to enable the perpetuation of the dissemination of Chinese music culture in response to global demand.

\section{References}

Alba, J. W., \& Hutchinson, J. W. (1987). Dimensions of Consumer Expertise. Journal of Consumer Research, 13(4), 411-454. http://dx.doi.org/10.1086/209080

An, N., \& Zhu, H. (2013). American magazine TIME's Geographical Imaginations of China: A Case Study on the Perspective of Orientalism. ACTA Geographica Sinica, 68, 1702-1713.

Axelrod, R. (1997). The Dissemination of Culture: A Model with Local Convergence and Global Polarization. The Journal of Conflict Resolution, 41(2), 203-226. http://dx.doi.org/10.1177/0022002797041002001

Beijing Foreign Studies University (BJFSU). (2015). Global Dynamic Database Resource on Chinese Culture $(G D D R C)$. Retrieved from http://www.gddrcc.org/index.do

Bellou, F. (2014). Cultural Awareness in Peace Operations: Effective Marketing or Strategic Communications. Procedia-Social and Behavioral Sciences, 148, 579-587. http://dx.doi.org/10.1016/j.sbspro.2014.07.083

Bresler, L. (1995). Ethnography, Phenomenology and Action Research in Music Education. The Quarterly Journal of Music Teaching and Learning, 8(3), 1-30. Retrieved from http://www-usr.rider.edu/ vrme/v8n1/vision/Bresler_Article_VRME.pdf

Burke, R. R., DeSarbo, W. S., Oliver, R. L., \& Robertson, T. S. (1988). Deception by Implication: An Experiment Investigation. Journal of Consumer Research, 14, 482-494. http://dx.doi.org/10.1086/209130

Burns, R. B. (1995). Introduction to Research Methods (2nd ed.). Australia: Longman.

CCOM. (2014). Handbook of the Celebration of the 10th Anniversary of Confucius Institute Series Music Cultural Exhibition and Performance Activities by CCOM.

CCOM. (2015). Handbook of the Same Song New Year Exchange Concert by Sino-Teenagers' Choirs \& “Center for the Exchange and Experience of Chinese and Foreign Music Cultures" Unveiling Ceremony.

CCOM. (2015). The official website of the Music Confucius Institute (MCI) Office of Central Conservatory of Music (CCOM). Retrieved from http://www.mci-ccom.org/default.asp 
Chadwick, S. (2012). Teachers as Agents in Botswana's Music Education: Challenges and Possibilities. Music Education Research, 14, 430-447. http://dx.doi.org/10.1080/14613808.2012.699955

Chen, H. G. (2008). The Role the Confucius Institute Plays in Cultural Dissemination. Academic Forum, 7 , 161-167. Retrieved from http://www.cnki.net/KCMS/detail/detail.aspx

Ding, S., \& Saunders, R. A. (2006). Talking up China: An analysis of China's Rising Cultural Power and Global Promotion of the Chinese Language. East Asia, 23(2), 3-33. http://dx.doi.org/10.1007/s12140-006-0021-2

Evans, L. (2010). Authenticity Online: Using Webnography to Address Phenomenological Concerns. Retrieved from http://www.inter-disciplinary.net/wp-content/uploads/2010/02/evanspaper.pdf

Gao, C., \& Li, M. (2015). The Use of Virtual Ethnography in Dissemination Research-An Example of QQ group of SZ People Living in Beijing. Investigation and Research, 1, 11-12.

Guo, Y. M. (2012). Tentative Analysis of the New Century Overseas Chinese Students Bidirectional Culture Dissemination in Overseas Universities. In Journal of Chongqing University of Posts and Telecommunications (Social Science Edition) (pp. 129-131, p. 141). Retrieved from http://www.cnki.net/KCMS/detail/detail.aspx

Hanban. (2016). The official website of the Confucius Institute Headquarters. Retrieved from $\mathrm{http}: / / \mathrm{www} \cdot h a n b a n . e d u . c n /$ confuciousinstitutes

Hartig, F. (2011). Confucius Institutes and the Rise of China. Journal of Chinese Political Science/Association of Chinese Political Studies, 17.

Hine, C. M. (2000). Virtual Ethnography. Thousand Oaks, CA: Sage Publications Ltd.

Hirst, P., \& Thompson, G. (1999). Globalization in Question. Cambridge: Polity.

Hou, R. F., \& Li, X. R. (2015). Confucius Institute: From Teaching Chinese Language to Drama Appreciation and Tea Tasting. Xin Jing Newspaper. Retrieved from http://news.163.com/14/1014/02/A8G0KAVD00014AED.html

Iyorza, S. (2014). Global Television and Cultural Promotion: Taming the Cultural Dilemma among Nigerian Youths. International Journal of Social Science and Humanity, 4(4), 308-310. http://dx.doi.org/10.7763/IJSSH.2014.V4.369

Jiang, X. L., \& Zhang, F. (2009). AMO Analysis on Promoting the International Communication of Chinese Culture. Journalism \& Communication, 16(5), 1-6. Retrieved from http://www.cnki.net/KCMS/detail/detail.aspx

Johnson, B., \& Christensen, L. (2004). Educational Research. Quantitative, Qualitative and Mixed Approaches. Boston: Pearson Education.

Li, J., \& Tian, X. H. (2015). A Global Experiment of the Internationalization of Chinese Higher Education-Ten Years of the Confucius School's Models, Experiences and Political Prescient. China Higher Education Research, 4, 37-43. Retrieved from http://www.cnki.net/KCMS/detail/detail.aspx

Liu, R. (2013). Research of the Constructional Factors and Operating System of Administrative Cultural Dissemination. Manager' Journal, 7, 63. Retrieved from http://www.cnki.net/KCMS/detail/detail.aspx

Munter, M. (1993). Cross-Cultural Communication for Managers. Business Horizons, 36, 69-78. http://dx.doi.org/10.1016/S0007-6813(05)80152-1

RDAM. (2015). The official website of the Royal Danish Academy of Music. Retrieved from $\mathrm{http}: / /$ english.dkdm.dk/Confucius-Institute

Smith, J. A., \& Osborn, M. (2003). Interpretative Phenomenological Analysis. In J. A. Smith (Ed.), Qualitative Psychology: A Practical Guide Research Methods (pp. 51-80). London: SAGE Publication.

Yang, Y. Y. (2012). Why Is It Important Awareness of Cross Culture Differences in Cultural Communication-Awareness of Cross Culture Differences Influences Cultural Communication. Overseas English, 10, 131-132. Retrieved from http://www.cnki.net/KCMS/detail/detail.aspx

Yuan, Y. (2004). A Good Example in Disseminating Chinese Culture in English. Shandong Foreign Languages Journal, 3, 78-80. Retrieved from http://www.cnki.net/KCMS/detail/detail.aspx

Zaharna, R. S. (1995). Understanding Cultural Preferences of Arab Communication Patterns. Public Relations Review, 21(3), 241-255. http://dx.doi.org/10.1016/0363-8111(95)90024-1 
Zeng, D. (2006). Theoretical Reflections on the Dissemination of Chinese Culture over the World. Journal of Yunnan Normal University (Humanities and Social Sciences), 3, 141-143. Retrieved from http://www.cnki.net/KCMS/detail/detail.aspx

Zhang, N. (2015). The Practice and Review on the Use of Virtual Ethnography in China. Journal of Sun Yat-Sen University (Social Science Edition), 256, 143-150. Retrieved from http://www.cnki.net/KCMS/detail/detail.aspx

\section{Copyrights}

Copyright for this article is retained by the author, with first publication rights granted to the journal.

This is an open-access article distributed under the terms and conditions of the Creative Commons Attribution license (http://creativecommons.org/licenses/by/3.0/). 